\title{
Valproate activates ERK signaling pathway in primary human hepatocytes
}

\author{
Michal Bitman ${ }^{\mathrm{a}}$, Radim Vrzal ${ }^{\mathrm{b}}$, Zdenek Dvorak $^{\mathrm{b}}$, Petr Pavek ${ }^{\mathrm{a}}$
}

\begin{abstract}
Aim. Valproic acid (VPA) is a widely-used anticonvulsant and mood-stabilizing agent. VPA is also known to inhibit histone deacetylases (HDACs) affecting the expression of numerous genes.

Methods. In the present study, we examined the effect of VPA on the extracellular signal-related kinase (ERK, p42/p44) pathway (Ras-Raf-MEK-ERK) belonging to the mitogen-activated protein kinases (MAPKs) pathways in primary human hepatocytes. In the liver, the pathway is associated with progression of hepatocellular carcinoma.

Results. We found that VPA in a therapeutically relevant concentration $(500 \mu \mathrm{M})$ activates the ERK pathway, as indicated by increased ERK Thr202/Tyr204 phosphorylation. Interestingly, a prototype HDAC inhibitor, trichostatin A, also activated ERK phosphorylation in primary human hepatocytes. These data suggest that HDAC inhibition might be the primary stimulus for ERK pathway activation in primary human hepatocytes. Notably, U0126, a MEK1 inhibitor, was ineffective in inhibiting ERK pathway activation, likely due to its metabolic deactivation in metabolically competent primary human hepatocytes.
\end{abstract}

Conclusion. We conclude that VPA activates the ERK pathway in primary human hepatocytes.

Key words: valproic acid, ERK pathway, cellular signaling

Received: October 27, 2011; Accepted with revision: March 28, 2012; Available online: June 1, 2012

http://dx.doi.org/10.5507/bp.2012.038

${ }^{a}$ Department of Pharmacology and Toxicology, Faculty of Pharmacy in Hradec Kralove, Charles University in Prague, Heyrovskeho 1203, 50005 Hradec Kralove, Czech Republic

${ }^{b}$ Department of Cell Biology and Genetics, Faculty of Science, Palacky University Olomouc, Slechtitelu 11, 78371 Olomouc

Corresponding author: Petr Pavek, e-mail: petr.pavek@faf.cuni.cz

\section{INTRODUCTION}

Valproic acid (VPA) has been used in the treatment of epilepsy for almost 40 years $^{1}$. Currently, it is used for its anti-seizure activity, as well as in the treatment of migraine and bipolar disorders ${ }^{2,3}$. Valproate is also used offlabel for the treatment of other psychiatric diseases. In the treatment of epilepsy, VPA is an effective broad-spectrum anticonvulsant used in the treatment of primary generalized tonic-clonic, absence, and partial seizures ${ }^{4,5}$. In the human brain, valproic acid primarily affects the function of the neurotransmitter $\gamma$-aminobutyric acid (GABA) by potentiating the inhibitory activity of GABA through several pathways, including the inhibition of GABA degradation, increased synthesis of GABA, and decreased GABA turnover ${ }^{6}$.

VPA is commercially available, for instance as Convulex, Depakine, or Stavzor. Although VPA is a welltolerated drug, hepatotoxicity ${ }^{7-9}$, bone marrow suppres$\operatorname{sion}^{10}$, decreased bone cell production, and osteomalacia are some of its adverse effects ${ }^{11}$. Even though it is extremely rare, the potential hepatotoxicity resulting in fatal liver failure is of major concern in treating patients with valproate $^{12,13}$. The mechanism of the hepatotoxicity is not clear $^{12}$. In addition to the hepatotoxicity, VPA is a human teratogen ${ }^{14}$.

It is well-known that VPA activates the mitogen-activated protein kinases (MAPKs) pathways in different cell lines ${ }^{15-18}$. In addition, it has been demonstrated that valproic acid interferes with multiple cellular regulatory mechanisms, including histone deacetylases, GSK $3 \alpha$ and $\beta$, Akt, the phosphoinositol pathway, the tricarboxylic acid cycle, GABA, and the OXPHOS system ${ }^{15}$. Valproate has been recognized as a histone deacetylases (HDAC) inhibitor (class I and IIa) in micromolar concentrations ${ }^{19}$. Therefore, VPA treatment promotes histone acetylation allowing the chromatin to adopt a relaxed structure which facilitates binding of various transcription factors. Thus, VPA is believed to induce global transcriptional changes. Concordantly, recently obtained data have shown that valproic acid affects cell growth, differentiation, apoptosis, and immunogenicity of cultured cancer cells and tumors ${ }^{15}$. Recently, we have identified VPA as the activator of pregnane $\mathrm{X}$ receptor (PXR) and inducer of CYP3A4 gene in primary human hepatocytes ${ }^{20}$.

The MAPKs (from the family of serine/threonine kinases) regulate diverse cellular programs by transferring extracellular signals to intracellular responses via downstream transcription factors. In mammals, there are more than a dozen MAPK enzymes that coordinately regulate cell proliferation, differentiation, motility, and survival. The best known MAPKs are the extracellular signal-regulated kinases 1 and 2 (ERK1/2), c-Jun amino-terminal kinases 1 to 3 (JNK1- to 3 ), p38 ( $\alpha, \beta, \gamma$, and $\delta$ ), and ERK5 $\left(\right.$ ref. $\left.^{21}\right)$. MAP kinases are activated after cell stimulation by a variety of growth factors and hormones and as well as during cell response to stress.

The extracellular signal-related kinase (ERK, p42/ p44) pathway (Ras-Raf-MEK-ERK) one of the MAPKs pathways is known to be crucial in many biological pro- 
cesses, such as cell proliferation, motility, survival, and carcinogenesis. Importantly, Ras-driven liver tumorigenesis by targeting its downstream effectors, including the Raf-MEK-ERK and PI3K-AKT-mTOR pathways, is a wellknown factor $^{22}$. Several in vitro studies showed that valproic acid specifically triggers phosphorylation of ERK, the upstream modulator of AP-1( ref. $^{16,17}$ ). Interestingly, it has been proposed that VPA activates pERK2 through attenuation of the PKA signalling pathway and this might be the common mechanism for VPA and lithium in the treatment of bipolar disorder ${ }^{23}$. In addition, although some reports suggest that HDAC inhibition mediated by VPA causes ERK pathway activation, there are also contradictory data observed in other tissues ${ }^{16,24,25}$.

In an earlier paper, we demonstrated that VPA activated ERK but not c-Jun-N-terminal kinase (JNK) nor p38 MAPKs in HEK cells ${ }^{26}$.

The effect of valproate on MAPKs activation in quiescent non-tumour primary human hepatocytes has however, not been studied.

For this reason, in the current paper, we concentrated on the effect of valproate on ERK pathway activation in three primary human hepatocyte cultures by Western blotting using phospho-specific antibodies. We also used trichostatin A (TSA), a model HDAC inhibitor, to elucidate whether HDAC inhibition leads to ERK pathway activation in primary human hepatocytes.

\section{METHODS}

\section{Chemicals}

VPA and trichostatin A (TSA) were purchased from Sigma-Aldrich (St. Louis, USA). TSA, an antifungal antibiotic produced by Streptomyces hygroscopicus, is a potent and specific inhibitor of HDACs from classes I, IIa and IIb leading to an increase in histone acetylation ${ }^{27,28}$. TSA is active at nanomolar concentration and causes accumulation of highly acetylated histone molecules in mammalian cells.

U0126 (purchased from Cell Signaling Technology, Inc., Boston, MA) is a chemically synthesized organic compound that inhibits Mitogen activated protein kinase Kinase 1 and 2 (also known as MEK1 and MEK2, with $\mathrm{IC}_{50}$ in nanomolar concentrations). U0126 inhibits both active and inactive MEK1 and MEK2 kinases $^{29}$.
LH18 preparation

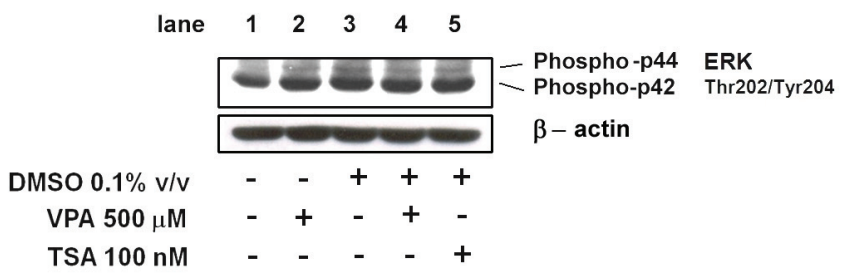

LH19 preparation

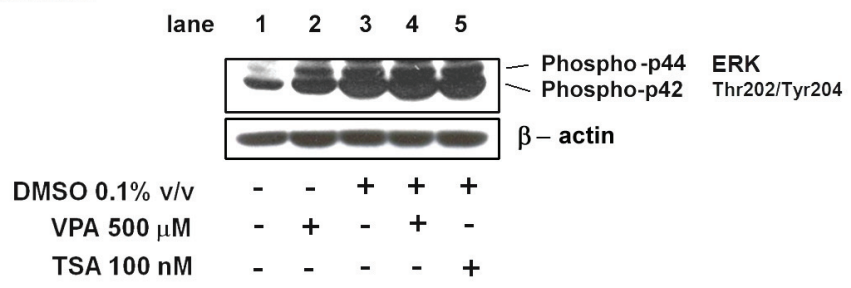

\section{LH21 preparation}

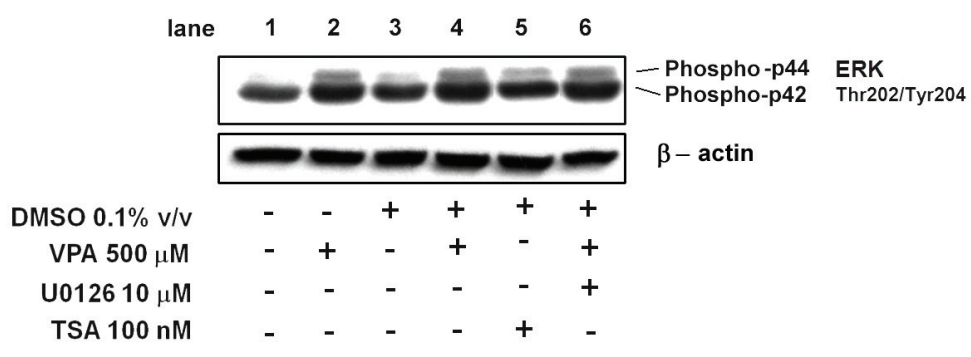

Fig. 1. The effects of VPA $(500 \mu \mathrm{M})$, TSA $(100 \mathrm{nM})$ and MEK1 inhibitor U0126 $(10 \mu \mathrm{M})$ on ERK pathway activation were examined in three independent primary human hepatocyte culturesLF18, LH19 and LH21. After isolation, the cells were plated on collagen-coated culture dishes at the density of $1.4 \times 10^{5}$ cells $/ \mathrm{cm}^{2}$. The medium was replaced with serum-free medium the following day, and the cells were allowed to get stabilized for an additional 48 to $72 \mathrm{~h}$ before the treatment with VPA $(500 \mu \mathrm{M})$, TSA $(10 \mathrm{nM})$ or U0126 $(10 \mu \mathrm{M})$ or their combinations, carried out for another $24 \mathrm{~h}$. We analyzed total cellular lysates by Western blotting with a phospho-specific Thr202/ Tyr204 ERK antibody and $\beta$-actin was used as a loading control. 


\section{Primary human hepatocyte cultures}

Human liver samples used in this study were obtained from several donors: (LH18) - a woman, 69 years old, tumor metastasis; and (LH19) - a woman, 46 years old, Caroli syndrome. LH21 hepatocyte preparation was described in our previous paper ${ }^{30}$. Hepatocytes were isolated as described previously ${ }^{31}$. After isolation, the cells were plated on collagen-coated culture dishes at the density of $1.4 \times 10^{5}$ cells $/ \mathrm{cm}^{2}$. The culture medium was enriched for plating with $2 \%$ FCS $(\mathrm{v} / \mathrm{v})$. The medium was replaced with serum-free medium the following day, and the cells were allowed to get stabilized for an additional 48 to $72 \mathrm{~h}$ before the treatment with VPA $(500 \mu \mathrm{M})$, TSA $(10 \mathrm{nM})$ or $\mathrm{U} 0126(10 \mu \mathrm{M})$ or their combinations, carried out for another $24 \mathrm{~h}$.

\section{Western blotting detection of proteins}

The total protein extracts from cultures were prepared as we have described elsewhere ${ }^{32,33}$. SDS-PAGE gels were run on a Hoefer apparatus according to the general procedure and protein transfer onto a polyvinylidene difluoride membrane was carried out. The membrane was stained with Ponceau S for control of transfer and then saturated with $8 \%$ non-fat dried milk in Tris-buffered saline (TBS) for $2 \mathrm{~h}$ at the room temperature. Blots were probed with primary antibodies against p42/44 MAPK phospho Thr202/Tyr204 (rabbit polyclonal antibody, ref 9101S) purchased from Cell Signaling Technology Inc. (Danvers, USA). $\beta$-actin was used as a loading control using goat polyclonal antipody (I-19; Santa Cruz Biotechnology). Chemiluminescence detection was performed using horseradish peroxidase conjugated secondary antibodies and an Amersham (GE Healthcare, Piscataway, USA) ECL kit. Films were scanned and the intensity of the bands was evaluated by densitometry.

\section{RESULTS}

In three independent primary human hepatocyte cultures, we examined the effects of VPA $(500 \mu \mathrm{M})$, TSA (100 nM) and MEK1 inhibitor U0126 (10 $\mu \mathrm{M})$ on ERK pathway activation. We analyzed total cellular lysates by Western blotting with a phospho-specific Thr202/Tyr204 ERK antibody.

We found that VPA activates phosphorylation of ERK in all three primary human hepatocyte cultures (Fig. 1).

In order to eliminate the potential effect of dimethyl sulfoxide (DMSO) used as a vehicle for VPA, TSA, and U0126, we also tested the effect of VPA in the absence of DMSO. In this case, PBS buffer was used as a vehicle for VPA. We observed a consistent effect of VPA on ERK phosphorylation irrespective of vehicle used (Fig. 1). Notably, DMSO itself activated ERK phosphorylation. Consistently, the effect of VPA dissolved in DMSO was weaker than the effect of VPA dissolved in PBS as a vehicle.

TSA also activated ERK phosphorylation, however, the effect was modest (Fig. 1). U0126, an ERK cascade inhibitor, had no effect on the ERK activation by VPA, which may be the consequence of U0126 metabolic deactivation in primary human hepatocytes.

Collectively, these data suggest that VPA activates the ERK pathway in therapeutically relevant concentrations in primary human hepatocytes.

\section{DISCUSSION}

VPA, an effective broad-spectrum anticonvulsant, has proven to affect the expression of a large number of genes $^{34}$. Some of these alterations in gene expression have been attributed to the HDAC inhibitory activity of VPA. However, it is also well-known that VPA activates different MAP kinases and other signaling pathways, such as GSK $3 \alpha$ and $\beta$, Akt, the phosphoinositol pathway, and the tricarboxylic acid cycle in different cells ${ }^{15}$.

Recently, we found that VPA slightly activated the extracellular signal-regulated kinase (ERK) and weakly inhibited c-Jun N-terminal kinase (JNK), while it had no effect on p38 kinase in HEK293 cells ${ }^{26}$.

However, a completely different pattern of MAPKs activation in other cell lines and tissues has been demonstrated in previous research. For example, VPA induced the phosphorylation of p38 but neither JNK nor extracellular signal-regulated kinase (ERK1/2) in lymphocytes ${ }^{35}$. In microglial cells, VPA increased the level of phosphop38 mitogen-activated protein kinase (MAPK), but had no effect on phospho-ERK and phospho-JNK MAPKs $\left(\right.$ ref. $\left.^{36}\right)$. These data suggest the need to study the effect of VPA in different cell lines and tissues. In addition, there is lack of information about the effect of VPA on cell signaling cascade activation in primary human cells derived from normal non-transformed tissues.

Hepatocellular carcinoma (HCC) is the most common and malignant type of liver cancer, which causes approximately 0.6 million deaths each year ${ }^{37}$. Importantly, activation of the Raf-MEK-ERK and PI3K-AKT-mTOR pathways has been reported in human HCCs (ref. ${ }^{22,38-41}$ ) and pharmacological inhibition of these pathways has exhibited significant anti-tumoral effects in clinical trials ${ }^{42}$.

Therefore, it is of importance to learn about the impact of VPA on MAPKs activation in normal hepatocytes. Our current data suggest that VPA activates the Ras-RafERK cascade in primary human hepatocyte cultures in therapeutically relevant concentrations $(500 \mu \mathrm{mol} / \mathrm{L})$. The therapeutic steady state Css level of VPA is about $100 \mu \mathrm{g} / \mathrm{mL}$ (corresponding to $600 \mu \mathrm{mol} / \mathrm{L}$ ) ( ref. $^{43}$ ). Serious intoxication is likely to occur at levels greater than $450 \mu \mathrm{g} / \mathrm{mL}$.

\section{CONCLUSION}

In conclusion, VPA activates the extracellular signalrelated kinase (ERK) pathway in primary human hepatocytes, which may be the consequence of its HDAC inhibitory activity. These data encourage further study 
of the effects of VPA on cellular signaling and gene expression profile in normal primary human hepatocytes with the aim of reducing the risk of HCC progression in patients treated with VPA.

\section{ACKNOWLEDGMENTS}

This work was supported by the Grant Agency of Charles University No. 118708/C to M. Bitman. Editing was financed by the grant No. 303/12/G163 from the Czech Science Foundation.

\section{REFERENCES}

1. Jeavons PM, Clark JE. Sodium valproate in treatment of epilepsy. $\mathrm{Br}$ Med J 1974;2:584-6.

2. Henry TR. The history of valproate in clinical neuroscience. Psychopharmacol Bull 2003;37 Suppl 2:5-16.

3. Lovell BV, Marmura MJ. Valproate semisodium ER for migraine and cluster headache prophylaxis. Expert Opin Drug Metab Toxicol 2011;6:495-504.

4. Rosenberg G. The mechanisms of action of valproate in neuropsychiatric disorders: can we see the forest for the trees? Cell Mol Life Sci 2007;64:2090-103.

5. Ben-Menachem E, Schmitz B, Tomson T, Vajda F. Role of valproate across the ages. Treatment of epilepsy in adults. Acta Neurol Scand Suppl 2006;184:14-27.

6. Johannessen CU. Mechanisms of action of valproate: a commentatory. Neurochem Int 2000;37:103-10.

7. Kingsley E, Tweedale R, Tolman KG. Hepatotoxicity of sodium valproate and other anticonvulsants in rat hepatocyte cultures. Epilepsia 1980;21:699-704.

8. Sussman NM, McLain LW, Jr. A direct hepatotoxic effect of valproic acid. Jama 1979;242:1173-4.

9. Granneman GR, Wang SI, Machinist JM, Kesterson JW. Aspects of the metabolism of valproic acid. Xenobiotica 1984;14:375-87.

10. Kishi T, Fujita N, Kawaguchi H, Ishimae M, Watanabe K, Tanaka T. Bone marrow suppression induced by high dose valproic acid. Arch Dis Child 1994:71:153-5

11. Krishnamoorthy G, Nair R, Sundar U, Kini P, Shrivastava M. Early predisposition to osteomalacia in Indian adults on phenytoin o valproate monotherapy and effective prophylaxis by simultaneous supplementation with calcium and 25-hydroxy vitamin D at recommended daily allowance dosage: a prospective study. Neurol India 2011;58:213-9.

12. Bjornsson E. Hepatotoxicity associated with antiepileptic drugs. Acta Neurol Scand 2008;118:281-90.

13. Ahmed SN, Siddiqi ZA. Antiepileptic drugs and liver disease. Seizure 2006;15:156-64.

14. Ornoy A. Valproic acid in pregnancy: how much are we endangering the embryo and fetus? Reprod Toxicol 2009;28:1-10.

15. Kostrouchova M, Kostrouch Z, Kostrouchova M. Valproic acid, a molecular lead to multiple regulatory pathways. Folia Biol (Praha) 2007; 53:37-49.

16. Michaelis M, Suhan T, Michaelis UR, Beek K, Rothweiler F, Tausch L Werz O, Eikel D, Zornig M, Nau H and others. Valproic acid induces extracellular signal-regulated kinase $1 / 2$ activation and inhibits apoptosis in endothelial cells. Cell Death Differ 2006;13:446-53.

17. Yuan PX, Huang LD, Jiang YM, Gutkind JS, Manji HK, Chen G. The mood stabilizer valproic acid activates mitogen-activated protein kinases and promotes neurite growth. J Biol Chem 2001;276:3167483.

18. Fei W, Aixi Y, Danmou X, Wusheng K, Zhengren P, Ting R. The mood stabilizer valproic acid induces proliferation and myelination of rat Schwann cells. Neurosci Res 2011;70:383-90.

19. Gottlicher M, Minucci $S$, Zhu P, Kramer OH, Schimpf A, Giavara S, Sleeman JP, Lo Coco F, Nervi C, Pelicci PG and others. Valproic acid defines a novel class of HDAC inhibitors inducing differentiation of transformed cells. Embo J 2001;20:6969-78.

20. Cerveny L, Svecova L, Anzenbacherova E, Vrzal R, Staud F, Dvorak Z, Ulrichova J, Anzenbacher P, Pavek P. Valproic acid induces CYP3A4 and MDR1 gene expression by activation of constitutive androstane receptor and pregnane $\mathrm{X}$ receptor pathways. Drug Metab Dispos 2007;35:1032-41

21. Cargnello M, Roux PP. Activation and function of the MAPKs and their substrates, the MAPK-activated protein kinases. Microbiol Mol Biol Rev 2011;75:50-83.

22. Whittaker S, Marais R, Zhu AX. The role of signaling pathways in the development and treatment of hepatocellular carcinoma. Oncogene 2010;29:4989-5005.

23. Boeckeler K, Adley K, Xu X, Jenkins A, Jin T, Williams RS. The neuroprotective agent, valproic acid, regulates the mitogen-activated protein kinase pathway through modulation of protein kinase $A$ signalling in Dictyostelium discoideum. Eur J Cell Biol 2006;85:104757.

24. Barter MJ, Pybus L, Litherland GJ, Rowan AD, Clark IM, Edwards DR, Cawston TE, Young DA. HDAC-mediated control of ERK- and PI3Kdependent TGF-beta-induced extracellular matrix-regulating genes. Matrix Biol;29:602-12.

25. Phiel CJ, Zhang F, Huang EY, Guenther MG, Lazar MA, Klein PS Histone deacetylase is a direct target of valproic acid, a potent anticonvulsant, mood stabilizer, and teratogen. J Biol Chem 2001;276:36734-41.

26. Vrzal R, Doricakova A, Novotna A, Bachleda P, Bitman M, Pavek P, Dvorak Z. Valproic acid augments vitamin $D$ receptor-mediated induction of CYP24 by vitamin D3: a possible cause of valproic acidinduced osteomalacia? Toxicol Lett 2011;200:146-53.

27. Kim TY, Bang YJ, Robertson KD. Histone deacetylase inhibitors for cancer therapy. Epigenetics 2006;1:14-23.

28. Yoshida M, Kijima M, Akita M, Beppu T. Potent and specific inhibition of mammalian histone deacetylase both in vivo and in vitro by trichostatin A. J Biol Chem 1990;265:17174-9.

29. Favata MF, Horiuchi KY, Manos EJ, Daulerio AJ, Stradley DA, Feeser WS, Van Dyk DE, Pitts WJ, Earl RA, Hobbs F and others. Identification of a novel inhibitor of mitogen-activated protein kinase kinase. J Biol Chem 1998;273:18623-32.

30. Vrzal R, Stejskalova L, Monostory K, Maurel P, Bachleda P, Pavek P, Dvorak Z. Dexamethasone controls aryl hydrocarbon receptor (AhR)mediated CYP1A1 and CYP1A2 expression and activity in primary cultures of human hepatocytes. Chem Biol Interact 2009;179:288-96.

31. Pichard-Garcia L, Gerbal-Chaloin S, Ferrini JB, Fabre JM, Maurel P. Use of long-term cultures of human hepatocytes to study cytochrome P450 gene expression. Methods Enzymol 2002;357:311-21.

32. Vrzal R, Daujat-Chavanieu M, Pascussi JM, Ulrichova J, Maurel $P$ Dvorak Z. Microtubules-interfering agents restrict aryl hydrocarbon receptor-mediated CYP1A2 induction in primary cultures of human hepatocytes via c-jun-N-terminal kinase and glucocorticoid receptor. Eur J Pharmacol 2008;581:244-54.

33. Henklova P, Vrzal R, Papouskova B, Bednar $P$, Jancova $P$, Anzenbacherova E, Ulrichova J, Maurel P, Pavek P, Dvorak Z. SB203580, a pharmacological inhibitor of p38 MAP kinase transduction pathway activates ERK and JNK MAP kinases in primary cultures of human hepatocytes. Eur J Pharmacol 2008;593:16-23.

34. Bosetti F, Bell JM, Manickam P. Microarray analysis of rat brain gene expression after chronic administration of sodium valproate. Brain Res Bull 2005;65:331-8.

35. Chen Q, Ouyang DY, Geng M, Xu LH, Zhang YT, Wang FP, He XH Valproic acid exhibits biphasic effects on apoptotic cell death of activated lymphocytes through differential modulation of multiple signaling pathways. J Immunotoxicol 2011;8:210-8.

36. Xie N, Wang C, Lin Y, Li H, Chen L, Zhang T, Sun Y, Zhang Y, Yin D, Chi Z. The role of p38 MAPK in valproic acid induced microglia apoptosis. Neurosci Lett;482:51-6.

37. Gomaa Al, Khan SA, Toledano MB, Waked I, Taylor-Robinson SD Hepatocellular carcinoma: epidemiology, risk factors and pathogenesis. World J Gastroenterol 2008;14:4300-8.

38. Downward J. Targeting RAS signalling pathways in cancer therapy. Nat Rev Cancer 2003;3:11-22.

39. Schmidt CM, McKillop IH, Cahill PA, Sitzmann JV. Alterations in guanine nucleotide regulatory protein expression and activity in human hepatocellular carcinoma. Hepatology 1997;26:1189-94. 
40. Calvisi DF, Ladu S, Gorden A, Farina M, Conner EA, Lee JS, Factor VM Thorgeirsson SS. Ubiquitous activation of Ras and Jak/Stat pathways in human HCC. Gastroenterology 2006;130:1117-28.

41. Newell P, Toffanin S, Villanueva A, Chiang DY, Minguez B, Cabellos L, Savic R, Hoshida Y, Lim KH, Melgar-Lesmes $P$ and others. Ras pathway activation in hepatocellular carcinoma and anti-tumoral effect of combined sorafenib and rapamycin in vivo. J Hepatol 2009;51:72533.

42. Llovet JM, Bruix J. Molecular targeted therapies in hepatocellular carcinoma. Hepatology 2008;48:1312-27.

43. Gugler R, Schell A, Eichelbaum M, Froscher W, Schulz HU. Disposition of valproic acid in man. Eur J Clin Pharmacol 1977;12:125-32. 